Case Report

\title{
Brachial artery perforator propeller flap reconstruction of post electrical burn defect axilla
}

\section{Surya Rao Rao Venkata Mahipathy*, Alagar Raja Durairaj, Narayanamurthy Sundaramurthy, Anand Prasath Jayachandiran, Suresh Rajendran}

\begin{abstract}
Department of Plastic and Reconstructive Surgery, Saveetha Medical College and Hospital, Thandalam, Kanchipuram, Tamil Nadu, India
\end{abstract}

Received: 30 June 2021

Accepted: 11 August 2021

\section{*Correspondence:}

Dr. Surya Rao Rao Venkata Mahipathy, E-mail: surya_3@hotmail.com

Copyright: (c) the author(s), publisher and licensee Medip Academy. This is an open-access article distributed under the terms of the Creative Commons Attribution Non-Commercial License, which permits unrestricted non-commercial use, distribution, and reproduction in any medium, provided the original work is properly cited.

\begin{abstract}
In the current scenario, propeller flaps are an attractive choice for single stage coverage of a large number of defects. They have a more reliable vascular pedicle than traditional flap and allow for greater freedom in design and wide mobilization and minimal donor-site morbidity. Harvesting of a propeller flap requires appropriate patient selection, preoperative planning, and meticulous dissection and these techniques greatly reduce the complication rates. Here, we present a case of a post burn raw area of the right axilla which was debrided and covered with a brachial artery perforator propeller flap.
\end{abstract}

Keywords: Brachial perforator, Propeller flap, Doppler, Upper limb

\section{INTRODUCTION}

Perforator-based propeller flaps are now considered as a safe and reliable option in reconstructing soft tissue defects through the body. A propeller flap is an island flap that moves around a stationary vascular axis, and reorients itself from one axis to the other. ${ }^{1}$ During the initial days of propeller flap surgery, the subcutaneous pedicle was thick which restricted the arc of rotation of these flaps. It is now possible to design propeller flaps based on a single perforator, called perforator-based propeller flaps which permit flap rotation up to $180^{\circ}$. The idea of free style perforator flaps allows great degree of freedom and intra operative maneuverability of the flap and can be harvested in any anatomical area where a sizable perforator can be found. ${ }^{1}$ There are a large series of reports of perforator-based propeller flaps in lower limb reconstruction, but very limited in the upper extremity. ${ }^{2,3}$

\section{CASE REPORT}

An 18 years old male with presented to the Department of Plastic and Reconstructive Surgery with a raw area of the right axilla since 1 month. He sustained an electrical burn 1.5 months back which was managed conservatively. He later developed skin necrosis of the right axilla which later formed an ulcer. There is no history of any comorbid illnesses. On examination, a defect measuring $6 \mathrm{x}$ $8 \mathrm{~cm}$ with superficial muscle necrosis was present in the right axilla with unhealthy tissue at the base (Figure 1). There was a serosanguinous discharge from the raw area with tender right axillary lymphadenopathy. We planned for debridement and good quality skin cover. Under general anesthesia, the raw area was debrided. Brachial artery perforator marked with hand held Doppler and the propeller flap was marked. One border of the flap incision was made and the brachial artery perforator was identified (Figure 2). The flap incisions were completed and the flap was propelled through 160 degrees and inset 
was given with 2-0 nylon sutures (Figure 3). Secondary raw area closed primarily with 2-0 nylon over closed suction drain. Post-operative period was uneventful and the sutures were removed on the 14th post-operative day when the flap was well settled. Patient was on regular follow up and the flap was well settled (Figure 4).

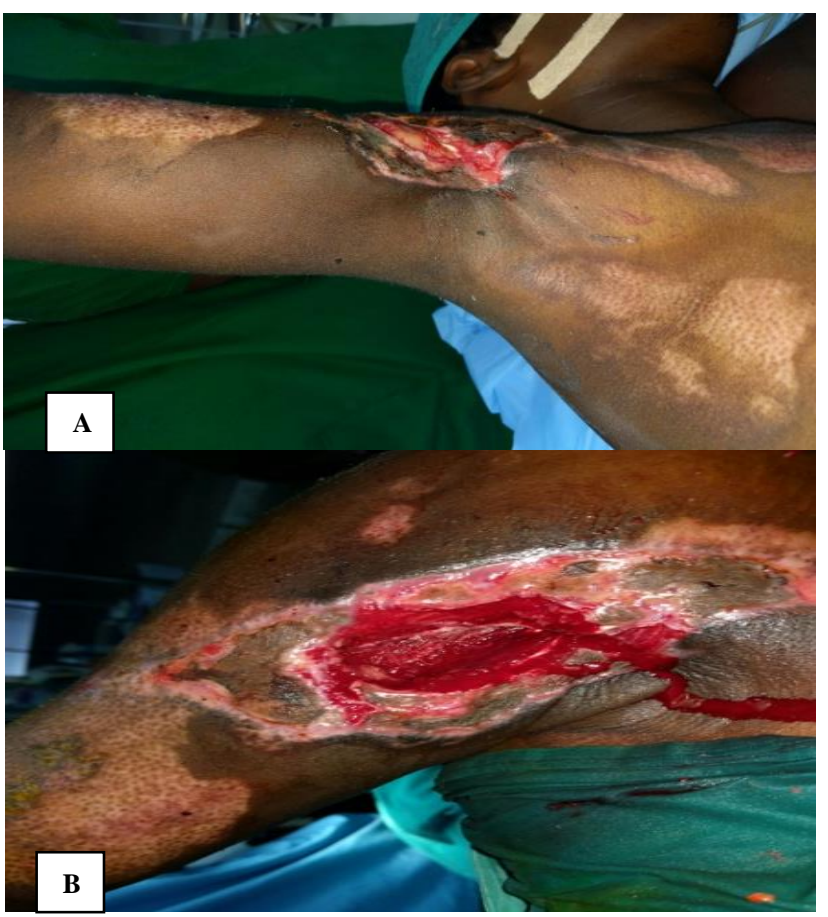

Figure 1: (A and B) Post electrical burn raw area right axilla.

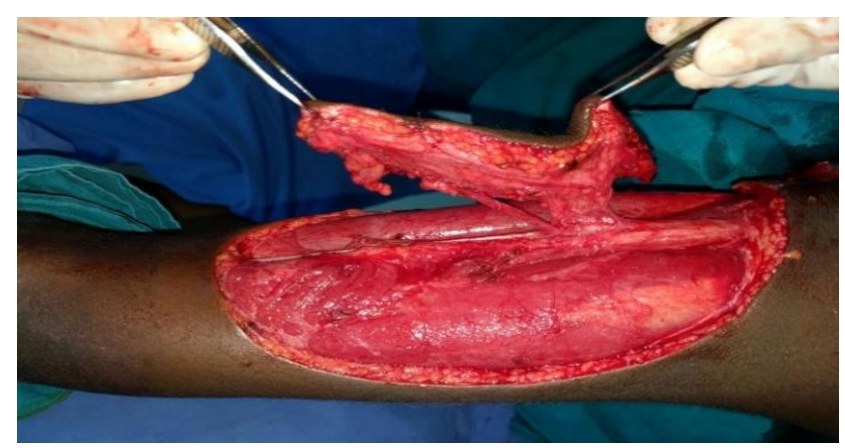

Figure 2: Brachial artery perforator propeller flap harvested.

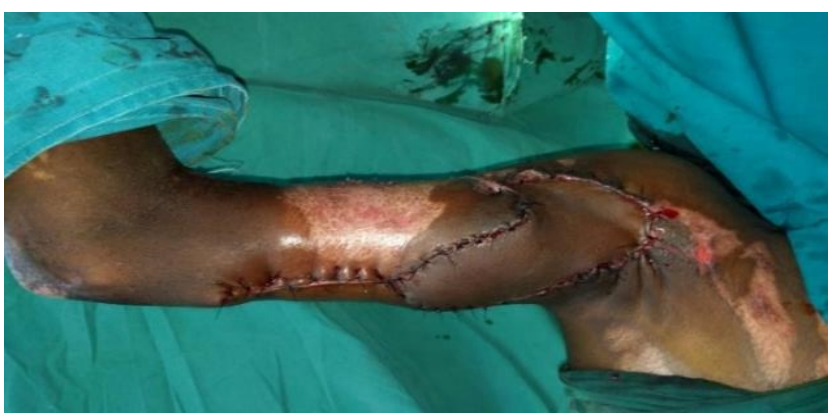

Figure 3: Immediate post-operative picture.

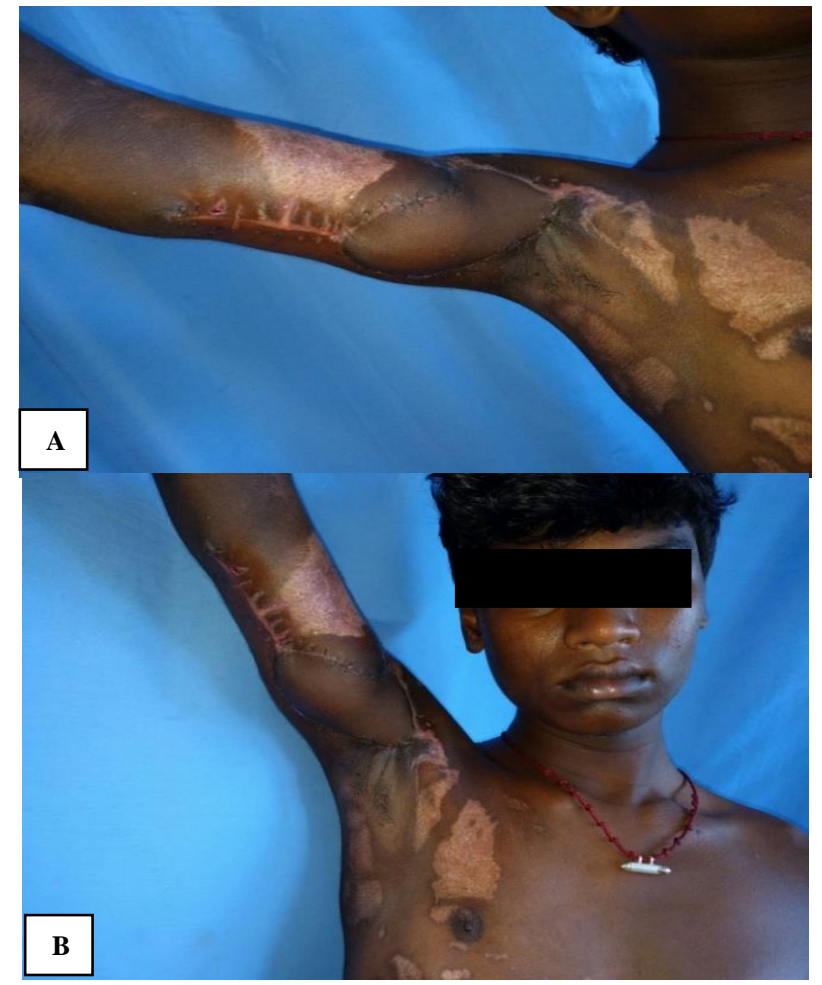

Figure 4: Post-operative picture at 3 months.

\section{DISCUSSION}

The term "propeller flap" was first used in 1991 by Hyakusoku et al to describe an adipocutaneous flap based on a central subcutaneous pedicle, with a shape resembling a propeller that was rotated 90 degrees. $^{4}$ Hallock in 2006, combined the concept of propeller flaps and perforator based flaps and reported a fasciocutaneous flap that was similar in shape to the one described by Hyakusoku but was based on a skeletonized perforating vessel and was rotated 180 degrees on an eccentric pivot point. ${ }^{5}$ Teo gave the greatest contribution to the surgical technique and the application of the perforator propeller flap. ${ }^{6}$ A perforator-based propeller flap for the upper limb combines the advantages of pedicled local flaps (good tissue match), pedicled regional flap $\left(180^{\circ}\right.$ arc of rotation), pedicled distant flap (reliable), and free flap (tissue away from zone of injury). ${ }^{1}$ According to the Gent consensus on perforator flaps and to the advisory panel of the first Tokyo meeting on perforator and propeller flaps, perforator propeller flaps should be named after their nutrient vessels. ${ }^{7,8}$ They can be classified according to the type of nourishing pedicle, subcutaneous pedicled propeller flap is based on a random subcutaneous pedicle and allows for rotations up to $90^{\circ}$, perforator-based pedicled propeller flap is based on a skeletonized perforator pedicle and is the most commonly used type of propeller flap which can be rotated up to $180^{\circ}$ and supercharged propeller flap where a superficial or perforating vein of the flap is anastomosed to a recipient vein or an extra artery is anastomosed to a second arterial pedicle of the flap to increase venous outflow or arterial inflow. Generally, most of the perforators in the upper 
extremity follow the intermuscular septum distally, but proximally they often pierce the muscle bellies. In the upper arm, they arise from the lateral septum between triceps and brachialis muscles and from medial intermuscular septum between triceps and biceps. ${ }^{9,10}$ The upper limb has more than 100 cutaneous perforators. ${ }^{11,12}$ These were divided into 16 vascular territories based on the deep trunk vessels from which these perforators arise by Chen et al. ${ }^{12}$ A perforator-based propeller flap can be designed on any of these perforators. The axilla, elbow, forearm, wrist, and hand represent the major anatomical areas that usually require reconstruction with propeller flaps. The complications of perforator-based propeller flaps include arterial and venous insufficiency and partial flap necrosis. ${ }^{13}$

\section{CONCLUSION}

Perforator-based propeller flaps are an invaluable reconstructive tool for most wounds and can be harvested from any part of the body. Proper patient selection, atraumatic handling of the tissues, especially the perforator during flap harvest and meticulous dissection minimizes the torsion effect gives a good outcome when using perforator-based propeller flaps for upper extremity reconstruction. There is also no to minimal donor site morbidity. Perforator-based propeller flaps are an alternative to free flaps when traditional flaps are not an option to reconstruct difficult wounds.

Funding: No funding sources

Conflict of interest: None declared

Ethical approval: Not required

\section{REFERENCES}

1. Ono S, Sebastin SJ, Yazaki N, Hyakusoku H, Chung KC. Clinical applications of perforator-based propeller flaps in upper limb soft tissue reconstruction. J Hand Surg Am. 2011;36:853-63.

2. Sananpanich K, Tu YK, Kraisarin J, Chalidapong P. Reconstruction of limb soft-tissue defects: Using pedicle perforator flaps with preservation of major vessels, a report of 45 cases. Injury. 2008;39(Suppl 4):55-66.

3. Innocenti M, Baldrighi C, Delcroix L, Adani R. Local perforator flaps in soft tissue reconstruction of the upper limb. Handchir Mikrochir Plast Chir. 2009;41:315-21.

4. Hyakusoku H, Yamamoto T, Fumiiri M. The propeller flap method. $\mathrm{Br} \mathrm{J}$ Plast Surg. 1991;44:53-4.

5. Hallock GG. The propeller flap version of the adductor muscle perforator flap for coverage of ischial or trochanteric pressure sores. Ann Plast Surg. 2006;56:540-2.

6. Teo TC. Perforator local flaps in lower limb reconstruction. Cirugia Plastica IberoLatinoamericana. 2006;32(4):15-292.

7. Blondeel PN, van Landuyt KHI, Monstrey SJM, Hamdi M, Matton GE, Allen RJ, et al. The "Gent" consensus on perforator flap terminology: preliminary definitions. Plastic and Reconstructive Surgery. 2003;112(5):1378-82.

8. Pignatti M, Ogawa R, Hallock GG, Mateev M, Georgescu AV, Balakrishnan G, et al. The "Tokyo" consensus on propeller flaps. Plastic and Reconstructive Surgery. 2011;127(2):716-22.

9. Sauerbier M, Unglaub F. Perforator flaps in the upper extremity. Clin Plast Surg. 2010;37:667-76.

10. Teo TC. The propeller flap concept. Clin Plast Surg. 2010;37:615-26.

11. Blondeel P, Morris S, Hallock G, Neligan P. Vascular supply of the integment of the upper extremity. In: Thomas BP, Tang M, Morris SF, editors. Perforator flaps. 1st ed. St. Louis, Missouri: QMP; 2006: 219-46.

12. Chen SH, Xu DC, Tang ML, Ding HM, Sheng WC, Peng TH. Measurement and analysis of the perforator arteries in upper extremity for the flap design. Surg Radiol Anat. 2009;31:687-93.

13. D'Arpa S, Toia F, Pirrello R, Moschella F, Cordova A. Propeller flaps: a review of indications, technique, and results. Biomed Res Int. 2014; 2014 : 986829.

Cite this article as: Mahipathy SRRV, Durairaj AR, Sundaramurthy N, Jayachandiran AP, Rajendran S. Brachial artery perforator propeller flap reconstruction of post electrical burn defect axilla. Int Surg J 2021;8:3211-3. 